Article

\title{
De-Ethylation and Cleavage of Rhodamine B by a Zirconium Phosphate/Silver Bromide Composite Photocatalyst
}

\author{
Monica Pica ${ }^{1, *(1)}$, Silvia Calzuola ${ }^{1}$, Anna Donnadio ${ }^{1}$, Pier Luigi Gentili ${ }^{2}$, Morena Nocchetti $^{1}$ \\ and Mario Casciola ${ }^{2, *}$ \\ 1 Department of Pharmaceutical Sciences, University of Perugia, Via del Liceo, 1, 06123 Perugia, Italy; \\ silvia.calzuola@alice.it (S.C.); anna.donnadio@unipg.it (A.D.); morena.nocchetti@unipg.it (M.N.) \\ 2 Department of Chemistry, Biology and Biotechnologies, University of Perugia, Via Elce di Sotto, 8, \\ 06123 Perugia, Italy; pierluigi.gentili@unipg.it \\ * Correspondence: monica.pica@unipg.it (M.P.); mario.casciola@unipg.it (M.C.); \\ Tel.: +39-075-585-5564 (M.P.); +39-075-585-5567 (M.C.)
}

Received: 15 November 2018; Accepted: 17 December 2018; Published: 21 December 2018

\begin{abstract}
A composite heterogeneous photocatalyst based on silver bromide was prepared by a reaction of silver exchanged zirconium phosphate $(\mathrm{ZrP})$ and $\mathrm{HBr}$. The $\mathrm{ZrP} / \mathrm{AgBr}$ composite containing $53 \mathrm{wt} \% \mathrm{AgBr}$ was tested in the photocatalytic degradation of Rhodamine B (RhB) and exhibited higher catalytic activity with respect to pure AgBr. As a matter of fact, the time needed to achieve a percentage of chromophore cleavage of about $90 \%$ was $3 \mathrm{~min}$ for the composite versus the 30 min needed for pure $\mathrm{AgBr}$. The $\mathrm{ZrP} / \mathrm{AgBr}$ composite turned out to be stable for at least three consecutive cycles. The UV-Vis spectra of the RhB solution, recorded at different irradiation times, were also decomposed and the concentration of the species formed by de-ethylation and cleavage processes during photocatalysis were calculated; the data obtained for the AgBr-based catalysis were also compared with those for the AgCl-based catalysis, and the degradation mechanism was suggested for both catalytic systems.
\end{abstract}

Keywords: zirconium phosphate; silver halides; photocatalysts; Rhodamine B

\section{Introduction}

Composite materials are obtained by combining two or more materials with different properties, with the aim of obtaining novel systems in which the single components work together to obtain new and unique properties [1]. Composite materials are used in several fields, for example in plastic materials, in which an inorganic component is dispersed in a polymer matrix to improve its mechanical properties, as well as to reduce permeation to liquid or gas species.

In catalysis, composite materials are often used to improve the catalytic efficiency of one or both components. In this regard, heterogeneous composite catalysts can be made of one catalytic active species supported on a solid matrix or consist of two active species combined together in order to promote specific interactions that achieve an enhancement of the catalytic activity. In an interesting review by Xie et al. published in 2010 [2], the authors give a detailed list of the various kinds of composite catalysts, organized according to the combination methods of the components, and also a list of the positive effects coming from the use of composite catalysts. Solid supports for active species in heterogeneous catalysis include alumina, silica, titania, zeolites, metal oxides, activated carbons, and polymers. These have been extensively studied [3], together with layered $\mathrm{Zr}(\mathrm{IV})$ phosphates and phosphonates [4]. 
Zirconium monohydrogenphosphate of $\alpha$-type $\left(\alpha-\mathrm{Zr}\left(\mathrm{HPO}_{4}\right)_{2} \cdot \mathrm{H}_{2} \mathrm{O}, \alpha-\mathrm{ZrP}\right)$ is a layered material with each layer consisting of $\mathrm{ZrO}_{6}$ octahedra sharing oxygens with six $\mathrm{HPO}_{4}$ tetrahedra through vertices. The $\mathrm{POH}$ groups point in the interlayer region and form hydrogen bonds with the water molecules [4-6]. It is a cation exchanger and has been used as a solid acid catalyst for several organic reactions. $\alpha$-ZrP has been also used as solid support for catalytic species such as metal cations, noble metal nanoparticles and metal complexes [4,7]. In 2015, composite photocatalysts made of $\alpha$ - $\mathrm{ZrP}$ and $\mathrm{AgCl}$ particles were tested in the photo-assisted degradation of Rhodamine B [8]. The authors took advantage of the ion exchange properties of $\alpha-\mathrm{ZrP}$ to prepare the composite through a two-step procedure: first, $\mathrm{Ag}(\mathrm{I})$-exchanged $\mathrm{ZrP}$ was prepared, then, $\mathrm{AgCl}$ was formed by the reaction of the above compound with $\mathrm{HCl}$. The procedure led to an intimate interspersion of the two crystalline phases, resulting in an enhanced photocatalytic activity of the composite with respect to $\mathrm{AgCl}$ and to the corresponding $\mathrm{ZrP} / \mathrm{AgCl}$ physical mixture. The authors proposed several arguments about the roles of $\mathrm{ZrP}$, including:

- reducing $\mathrm{AgCl}$ particle growth and aggregation, thus increasing the number of catalytic active sites;

- $\quad$ promoting the chemisorption of the protonated dye on its surface and, in turn, the degradation of the chromophore;

- creating an acidic medium that promotes the formation of species with higher oxidative potential.

Several authors evaluated and compared the behavior of different silver halides in photocatalysis. They found that the partial chemical reduction of $\mathrm{Ag}(\mathrm{I})$ ions from the $\mathrm{AgX}$ crystal lattice led to the formation of Ag nanoparticles (NPs) and, consequently, of Ag@AgX heterojunctions which improve the visible light absorption by the photocatalysts thanks to the surface plasmon resonance of the $\mathrm{Ag}$ NPs [9-16].

Moreover, literature data on the photodegradation of $\mathrm{RhB}$ proved that it occurs through two pathways $[17,18]$ :

- de-ethylation, which involves the dye molecules adsorbed on the catalyst surface and occurs in a stepwise manner, leading to the formation of several partially de-ethylated species and finally to the completely de-ethylated form, Rhodamine (Rh);

- chromophore structure cleavage, mainly occurring in the solution bulk.

The physico-chemical properties of the photocatalyst affect the preference toward one or the other pathway by promoting "molecular selective modification or deeply extent photooxidation" [18]. On the basis of these considerations, it seemed of interest to investigate the catalytic properties of $\mathrm{ZrP} / \mathrm{AgBr}$ composites in the photodegradation of $\mathrm{RhB}$. The $\mathrm{ZrP} / \mathrm{AgBr}$ system was prepared according to [8], then characterized by X-Ray diffraction (XRD), Diffusive Reflectance Spectroscopy (DRS) and Scanning Electron Microscopy (SEM) analyses. The photocatalytic behavior of both pure AgBr and $\mathrm{ZrP} / \mathrm{AgBr}$ was evaluated, as well as the contribution of the above degradation pathways to the $\mathrm{RhB}$ disappearance. Comparisons with the performances of pure $\mathrm{AgCl}$ and of a similar $\mathrm{ZrP} / \mathrm{AgCl}$ system were also reported.

\section{Results and Discussion}

\subsection{Preparation and Characterization of the Photocatalyst}

Nanocrystalline silver exchanged $\mathrm{ZrP}$ was employed for the precipitation of $\mathrm{AgBr}$ particles. The choice of this material (instead of the corresponding microcrystalline one) was done on the basis of the results obtained by preliminary experiments, carried out by using microcrystalline silver exchanged $\mathrm{ZrP}$ for the synthesis of $\mathrm{AgCl}$ particles (unpublished results).

It was found that the morphology of the micro- $\mathrm{ZrP} / \mathrm{AgCl}$ composites was completely different from that of nano- $\mathrm{ZrP} / \mathrm{AgCl}$. 
As shown in Supplementary Figure S1, $\mathrm{AgCl}$ particles with an average particle size of about $350 \mathrm{~nm}$ decorated the surface of the ZrP microcrystals (Supplementary Figure S1A), while they are completely embedded in the nanocrystalline ZrP powder (Supplementary Figure S1B), making their identification difficult. The average size of the particles in Supplementary Figure S1B was around $230 \mathrm{~nm}$.

These data suggested that microcrystalline $\mathrm{ZrP}$ is less effective in reducing AgX particle growth and aggregation.

Moreover, the fact that the $\mathrm{AgCl}$ particles are completely surrounded by $\mathrm{ZrP}$ nanoparticles, and not simply supported, should better prevent leaching and aggregation of the $\mathrm{AgX}$ particles during photocatalytic tests.

According to these preliminary findings, the $\mathrm{ZrP} / \mathrm{AgBr}$ composite material, containing $53 \mathrm{wt} \%$ $\mathrm{AgBr}$, has been prepared by the reaction of silver(I) exchanged $\mathrm{ZrP}$ ( $\mathrm{ZrPAg}$ ) with an excess of $\mathrm{HBr}$ solution, by using a procedure similar to that reported in [8].

Figure 1 shows the XRD patterns of $\operatorname{ZrP}(\mathrm{A})$ and the $\mathrm{ZrPAg}$ precursor (B). Figure $1 \mathrm{~A}$ refers to nanocrystalline $\alpha-\mathrm{Zr}\left(\mathrm{HPO}_{4}\right)_{2} \cdot \mathrm{H}_{2} \mathrm{O}$, with the typical reflection at $11.6^{\circ} 2 \theta$ due to the $(002)$ crystallographic planes, corresponding to an interlayer distance of $7.6 \AA$; the peaks at $19.77^{\circ}, 24.96^{\circ}$, $33.81^{\circ} 2 \theta$ are respectively assigned to the (002), (110), (112), (020) crystallographic planes.

From pattern comparison, the results show that the $\mathrm{ZrPAg}$ sample consists of two phases, $\mathrm{Zr}\left(\mathrm{AgPO}_{4}\right)_{2}$ and residual $\alpha-\mathrm{ZrP} \cdot \mathrm{H}_{2} \mathrm{O}$. After treatment with $\mathrm{HBr}$, besides the reflections of $\alpha-\mathrm{ZrP} \cdot \mathrm{H}_{2} \mathrm{O}$, those of cubic $\mathrm{AgBr}$ appeared at $30.9^{\circ}, 44.3^{\circ}, 55.0^{\circ}, 64.5^{\circ}, 73.2^{\circ}, 81.6^{\circ} 2 \theta$, corresponding to the (200), (220), (222), (400), (420) and (422) crystallographic planes, respectively (Joint Committee on Powder Diffraction Standards, JCPDS, No. 79-0149) (Figure 2).

We evaluated the crystalline domain size of $\mathrm{AgBr}$, from the full width at half maximum, by using the Scherrer equation:

$$
L=\frac{K \lambda}{\beta \cos \theta}
$$

where $\lambda$ is the $X$-ray wavelength in nanometers $(\mathrm{nm}), \beta$ is the peak width of the diffraction peak profile at half maximum height (corrected for the instrumental broadening) and $K$ is a constant related to crystallite shape, taken as 0.9 for cubic unit cells.

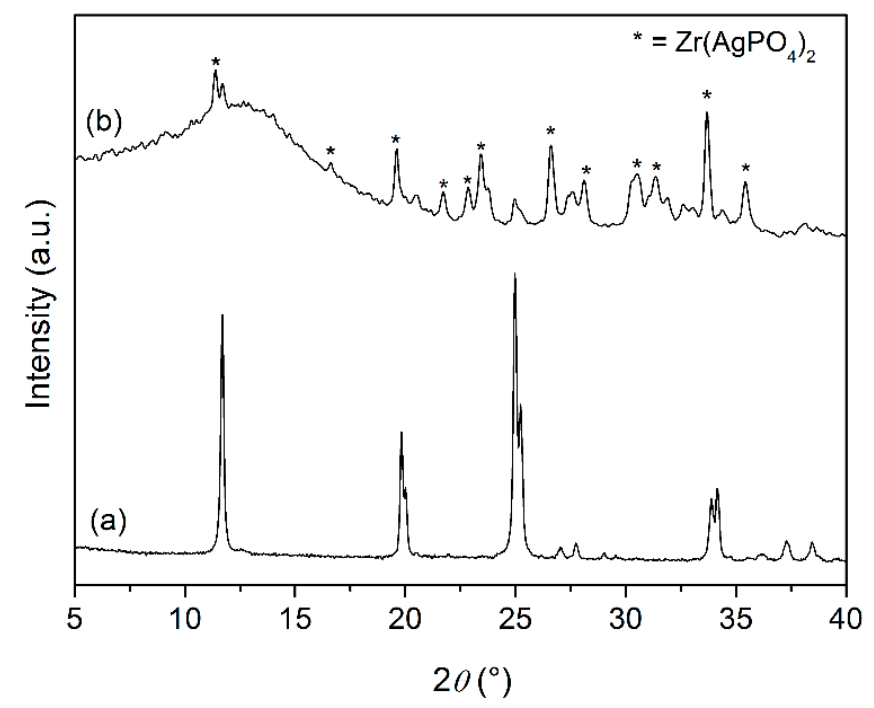

Figure 1. XRD patterns of $\alpha-\mathrm{ZrP} \cdot \mathrm{H}_{2} \mathrm{O}$ (a) and $\mathrm{ZrPAg}$ (b). Peaks labelled with an asterisk refer to the $\mathrm{Zr}\left(\mathrm{AgPO}_{4}\right)_{2}$ phase. a.u. = arbitrary units. 


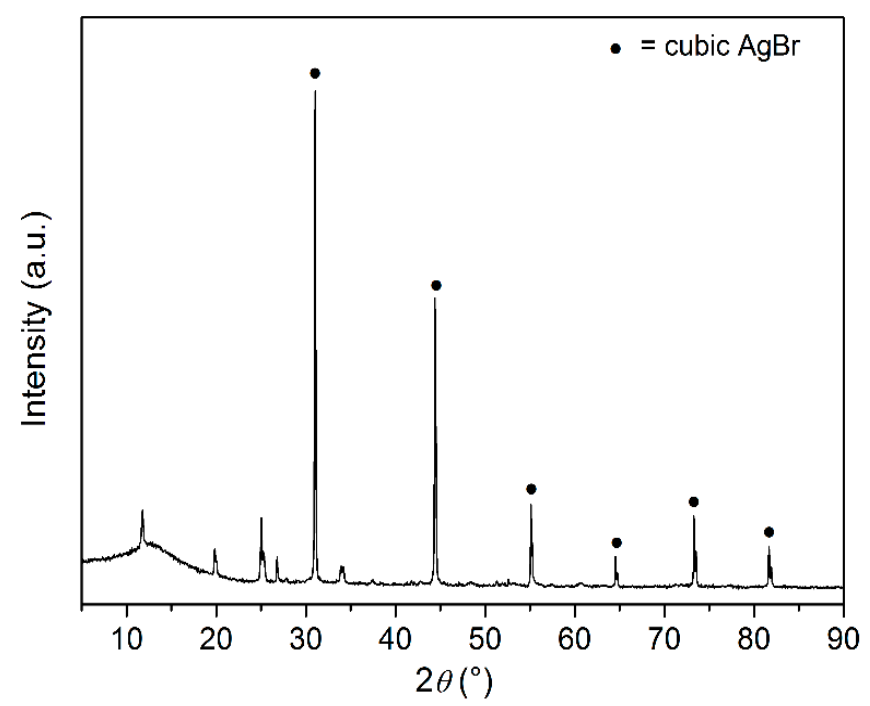

Figure 2. $\mathrm{XRD}$ pattern of $\mathrm{ZrP} / \mathrm{AgBr}$. Peaks labelled with black dots refer to the cubic AgBr phase.

From this calculation, we obtained an average value for the $\mathrm{AgBr}$ crystalline domain size of about $280 \mathrm{~nm}$. This value is similar to that obtained for $\mathrm{AgCl}$ particles in $\mathrm{ZrP} / \mathrm{AgCl}$ composites [8].

The particle morphology of the pure $\mathrm{AgBr}$ and $\mathrm{ZrP} / \mathrm{AgBr}$ samples was studied by scanning electron microscopy (SEM). Figure 3 shows a representative SEM image of the pure AgBr sample, consisting of micrometric particles and aggregates, with size ranging from $0.5 \mu \mathrm{m}$ to about $3 \mu \mathrm{m}$.

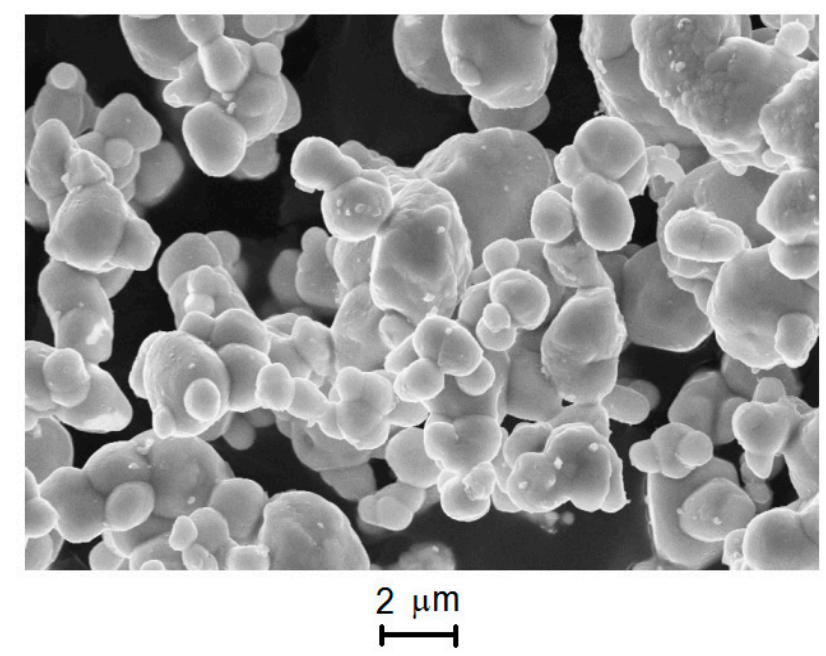

Figure 3. Representative SEM image of the pure $\mathrm{AgBr}$ sample used as reference.

The morphology of the $\mathrm{ZrP} / \mathrm{AgBr}$ composite (Figure 4) is completely different and more closely resembles pure $\mathrm{ZrP}$, consisting of nanometric particles with an almost uniform size, than that of pure $\mathrm{AgBr}$. Indeed, it is not easy to identify the $\mathrm{AgBr}$ particles, although its mass fraction is comparable with that of $\mathrm{ZrP}$. One could conclude that $\mathrm{AgBr}$ and $\mathrm{ZrP}$ have similar particle size, of the order of hundreds of nanometers, in agreement with the estimation obtained by the Scherrer equation. This finding proves that in the presence of $\mathrm{ZrP}$, the $\mathrm{AgBr}$ particle growth and aggregation is limited to some extent.

Further evidence of the different size of the $\mathrm{AgBr}$ particles in the pure sample and in the composite came from the absorption spectra of the two materials, which are shown in Kubelka-Munk units in Figure 5. Both materials begin to absorb at wavelengths shorter than $485 \mathrm{~nm}$. AgBr (black trace) absorbs more strongly than $\mathrm{ZrP} / \mathrm{AgBr}$ (red trace). In fact, $\mathrm{AgBr}$ appears as a more saturated yellow powder than the pale yellow of $\mathrm{ZrP} / \mathrm{AgBr}$. According to the procedure explained previously, the 
analysis of the absorption spectrum of $\mathrm{AgBr}$ reveals the presence of at least two direct band gaps: one at $439 \mathrm{~nm}(2.83 \mathrm{eV})$ and the other at $409 \mathrm{~nm}(3.04 \mathrm{eV})$. The presence of more than one band gap confirms that our $\mathrm{AgBr}$ consists of a dimensional distribution of its particles. $\mathrm{ZrP} / \mathrm{AgBr}$ is also a material with multiple band gaps. It shows at least two band gaps: one at $398 \mathrm{~nm}(3.12 \mathrm{eV})$ and the other at 352 $\mathrm{nm}(3.53 \mathrm{eV})$. The latter corresponds to the band gap of the host ZrP matrix (see [8] for the absorption spectrum of $\mathrm{ZrP}$ ); the former is due to the $\mathrm{AgBr}$ particles. Since the greater the band gap, the smaller the particle dimensions, [19], these results confirm that in our $\mathrm{ZrP} / \mathrm{AgBr}$ composite, the AgBr particles are smaller than those in our pure AgBr.
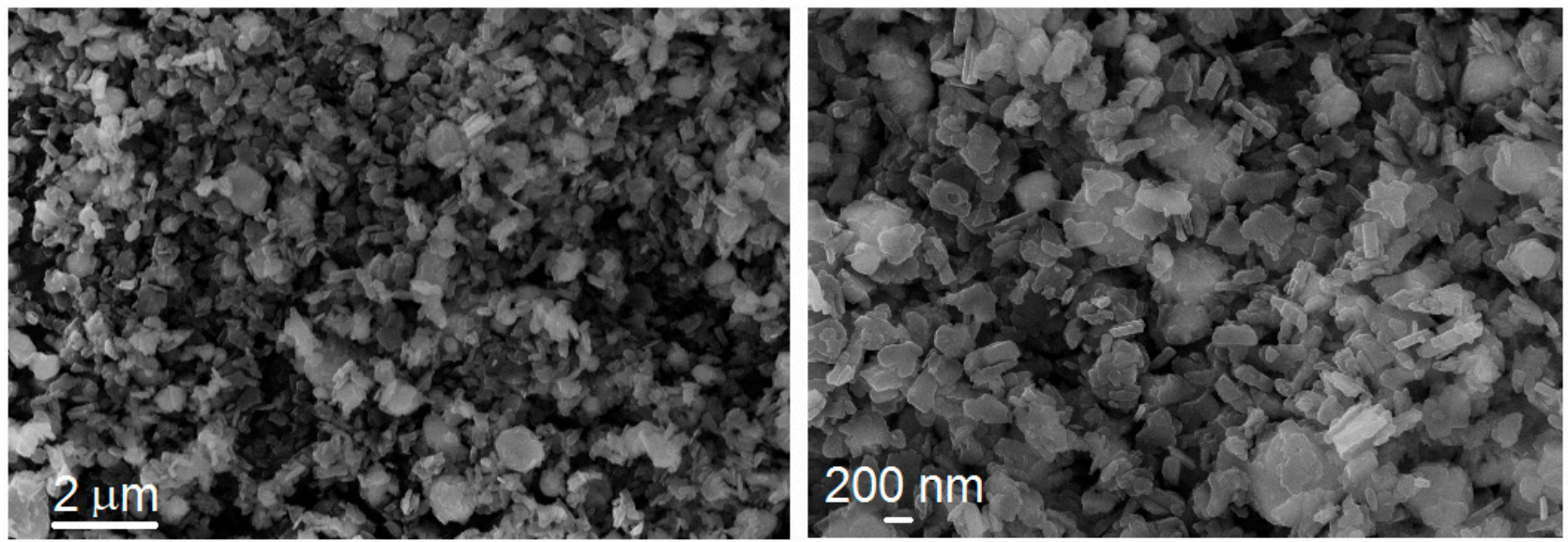

Figure 4. Representative SEM images of $\mathrm{ZrP} / \mathrm{AgBr}$ at different magnifications.

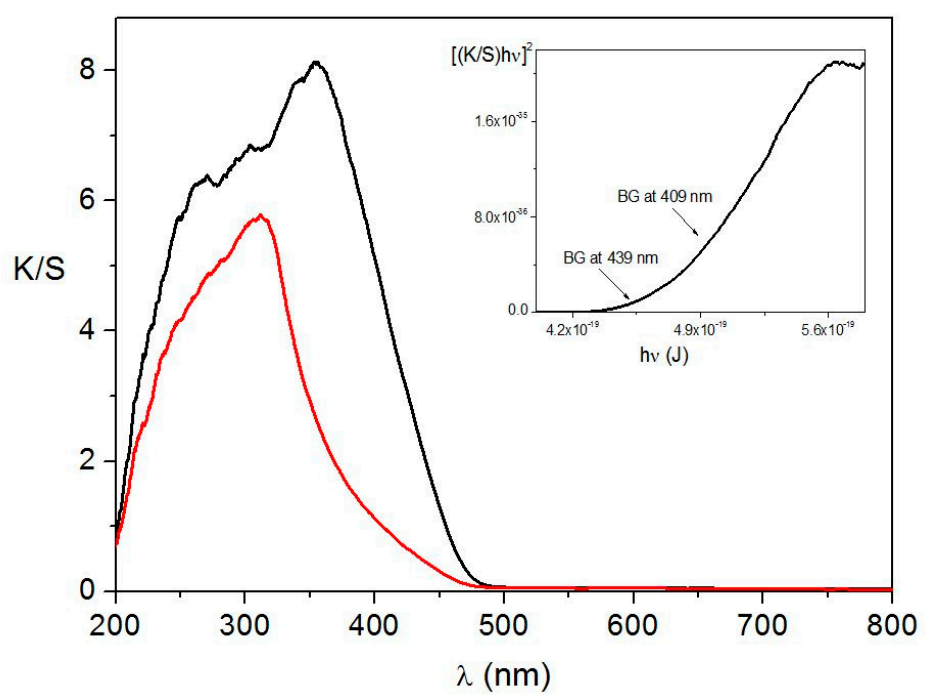

Figure 5. Absorption spectra in Kubelka-Munk units (K/S, where $\mathrm{K}$ and $\mathrm{S}$ are the apparent absorption and scattering coefficients, respectively) of $\mathrm{AgBr}$ (black trace) and $\mathrm{ZrP} / \mathrm{AgBr}$ (red trace) as a function of the wavelength, $\lambda$. The two direct band gaps of $\mathrm{AgBr}$ are highlighted in the inset. $\lambda=$ wavelength. $\mathrm{BG}=$ band gap.

\subsection{Photocatalytic Tests}

We studied the photocatalytic properties of the $\mathrm{ZrP} / \mathrm{AgBr}$ composite in the photodegradation of Rhodamine B (RhB), a cationic dye with four ethyl groups bonded to two nitrogen atoms (Figure 6).

In the present work, a weighed amount of the freshly prepared photocatalyst was suspended in $25 \mathrm{~mL}$ of a $1 \times 10^{-5} \mathrm{M}$ RhB solution. The amount of powdered catalyst used in each test has been reported in Table 1. 
<smiles>CCN(CC)c1ccc2c(-c3ccccc3C(=O)O)c3ccc(=[N+](CC)CC)cc-3oc2c1</smiles>

Figure 6. Chemical structure of Rhodamine B (RhB).

Table 1. Amount of catalysts used in each experiment, expressed as mg of photocatalyst, or mg of $\mathrm{AgBr}$, per $\mathrm{mL}$ of $\mathrm{RhB}$.

\begin{tabular}{ccc}
\hline Sample & mg Photocatalyst/mL RhB & mg AgBr/mL RhB \\
\hline $\mathrm{AgBr}$ & 1.1 & 1.1 \\
\hline \multirow{2}{*}{$\mathrm{ZrP} / \mathrm{AgBr}$} & 2.1 & 1.1 \\
& 1.4 & 0.73 \\
& 0.85 & 0.45 \\
\hline
\end{tabular}

After equilibration in the dark with the catalyst, the UV-Vis spectra of the RhB solution were collected at given intervals of irradiation time. Catalytic tests under irradiation in the presence of pure $\mathrm{ZrP}$ has been reported in a previous paper and proved that it did not have significant catalytic activity toward the photodegradation of $\mathrm{RhB}$ [8].

The results obtained with the pure AgBr sample are shown in Figure 7. The decrease in the absorbance after equilibration in the dark $(t=0 \mathrm{~min})$ was due to the adsorption of the dye on the catalyst surface. During irradiation, the absorbance decreases and the absorption maximum $\left(\lambda_{\mathrm{m}}\right)$ slowly shifts toward lower $\lambda$ values, from $554 \mathrm{~nm}$ to $497 \mathrm{~nm}$. Watanabe et al. in 1977 proved that this ipsochromic shift of $\lambda_{\mathrm{m}}$, observed by illumination of the $\mathrm{RhB}$ solution in the presence of a photocatalyst, is due to de-ethylation occurring in a stepwise manner, and to cleavage processes [18].

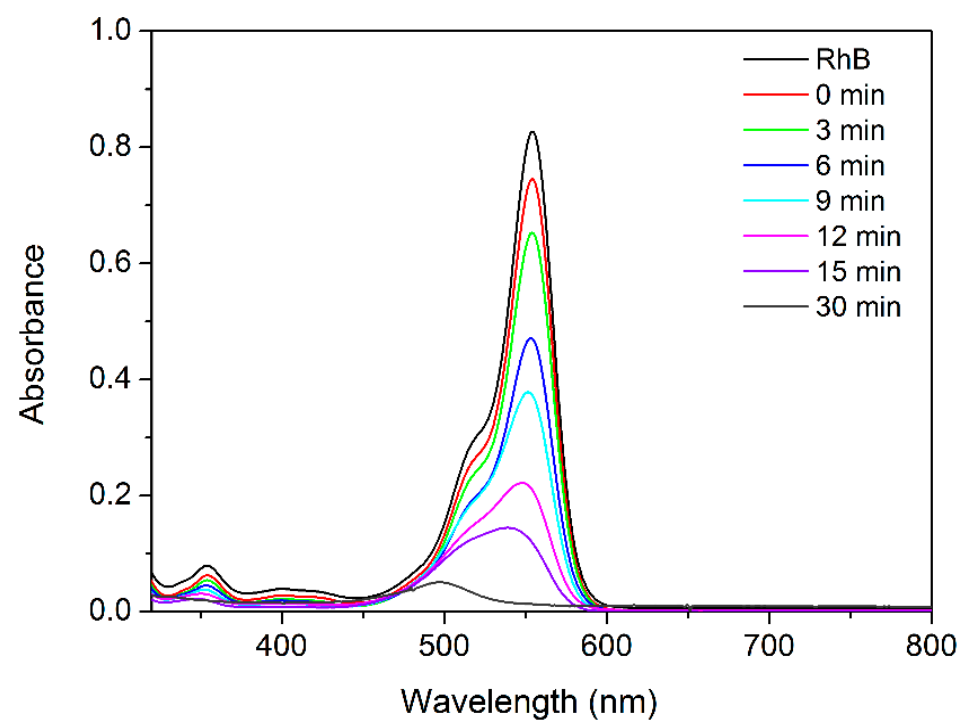

Figure 7. Temporal changes of the absorption spectrum of the RhB solution in the presence of pure AgBr.

In order to assess the contribution of de-ethylation and cleavage processes to the RhB degradation, it can be observed, on the basis of the literature [19], that the absorption of the cleaved species lies in the UV region. Therefore, the absorbance, measured at time $t$ and wavelengths $\lambda$ in the range $450-600 \mathrm{~nm}\left(A_{\lambda}(t)\right)$, depends on the concentrations of RhB and of its de-ethylated species. 
$A_{\lambda}(t)$ can be written as:

$$
A_{\lambda}(t)=d \sum_{i=1}^{5} \varepsilon_{i, \lambda} C_{i}(t)
$$

where $d=$ path length of the light beam; $\varepsilon_{i, \lambda}=$ molar extinction coefficient of the $i$ species at the wavelength $\lambda ; i=1$ for RhB; $i=2$ for $\mathrm{N}, \mathrm{N}, \mathrm{N}^{\prime}$-triethylated $\mathrm{Rh} ; i=3$ for $\mathrm{N}, \mathrm{N}^{\prime}$-diethylated $\mathrm{Rh} ; i=4$ for N-ethylated Rh; $i=5$ for Rh; and $C_{\mathrm{i}}(t)=$ concentration of the $i$ species at time $t$.

The determination of $A_{\lambda}(t)$ at five suitable $\lambda$ values and the knowledge of the molar extinction coefficients of Rhodamine B and of the four de-ethylated species at each $\lambda$ value allows us to set up a system of five linear equations whose solution provides the five unknown concentrations. To this aim, we considered the absorbances measured, at a given time, for the $\lambda$ values of $554 \mathrm{~nm}, 539 \mathrm{~nm}$, $522 \mathrm{~nm}, 510 \mathrm{~nm}$ and $497 \mathrm{~nm}$, which correspond to the absorption maximum of the species (1), (2), (3), (4) and (5), respectively. As a consequence, the molar extinction coefficient of each species has a significantly higher value in at least one equation, and each species is adequately represented in the equation system. The values of the molar extinction coefficients for each wavelength $\left(\varepsilon_{i, \lambda}\right)$ were derived from the Watanabe paper [19].

Figure 8 shows the RhB relative concentration, $C_{1}(t) / C_{1}(0)$, where $C_{1}(0)$ is the concentration of RhB at $t=0 \mathrm{~min}$, together with the relative total concentration of the de-ethylated species $\left(\sum_{i=2}^{5} C_{i}(t) / C_{1}(0)\right)$, and the relative concentration of the cleaved species (that is $1-\sum_{i=1}^{5} C_{i}(t) / C_{1}(0)$ ), as a function of time. The concentration of RhB decreased over time and approached zero at $30 \mathrm{~min}$. As shown, the disappearance of $\mathrm{RhB}$ is due to both de-ethylation and cleavage; the relative concentration of the de-ethylated species first increases and reaches a maximum $(\approx 0.4)$ around $12-15 \mathrm{~min}$, then decreases to $\approx 0.1$ at $30 \mathrm{~min}$.

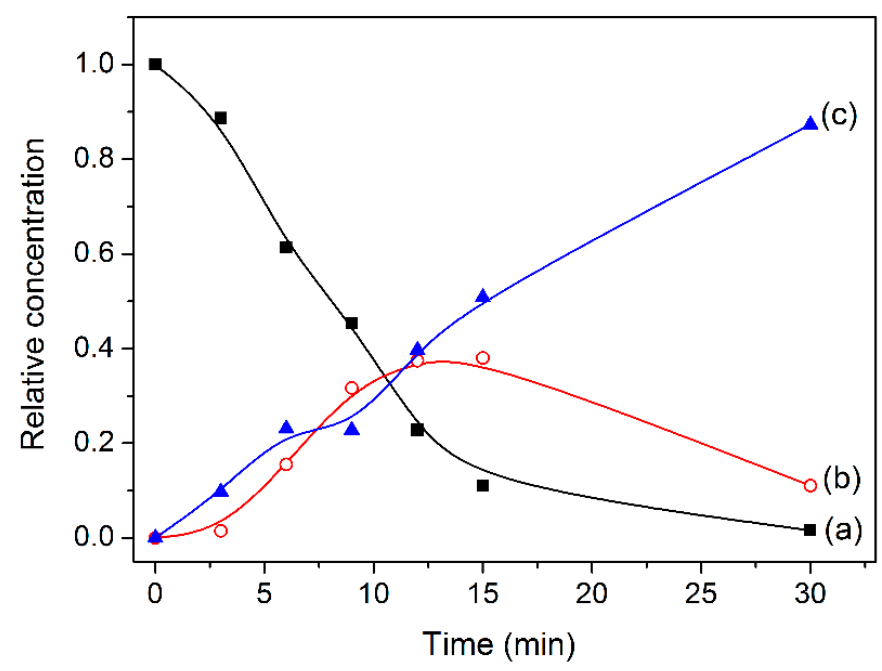

Figure 8. Relative concentration of $\operatorname{RhB}(\mathrm{a})$; de-ethylated species (b) and cleaved species (c) as a function of time, calculated according to Equation (2), for the catalytic test with pure AgBr.

The concentration of the de-ethylated and cleaved species is comparable in the time range 0-12 min, while cleavage prevails on de-ethylation for longer time than $15 \mathrm{~min}$.

The half-life of $\mathrm{RhB}\left(t_{1 / 2}\right)$ was $7.92 \mathrm{~min}$, while the percentage of chromophore cleavage was around $91 \%$ after $30 \mathrm{~min}$.

Kinetic studies in the presence of $\mathrm{ZrP} / \mathrm{AgBr}$ were carried out by using different amounts of photocatalyst; the maximum amount was chosen in order to have an AgBr content as high as that used for the test with the pure sample.

The temporal evolution of the UV-Vis spectra of RhB in the three experiments with $\mathrm{ZrP} / \mathrm{AgBr}$ are shown in Figure 9. An ipsochromic shift of $\lambda_{\mathrm{m}}$ was observed, and an almost complete disappearance 
of the band in the visible region (chromophore cleavage $>90 \%$ ) occurred within a maximum of $6 \mathrm{~min}$, $12 \mathrm{~min}$ and $15 \mathrm{~min}$ in the presence of $1.1 \mathrm{mg}, 0.73 \mathrm{mg}, 0.45 \mathrm{mg} \mathrm{AgBr} / \mathrm{mL} \mathrm{RhB}$, respectively.
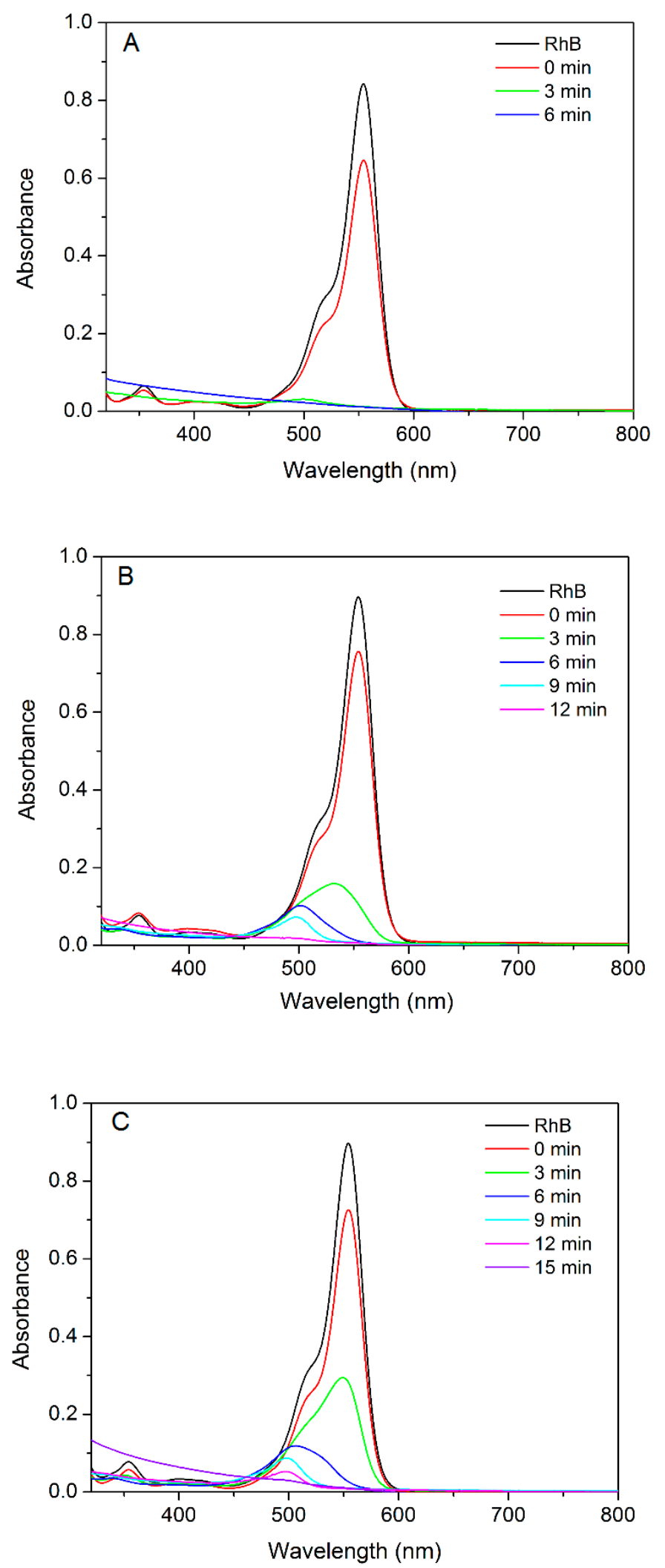

Figure 9. Temporal changes of the absorption spectrum of the RhB solution in the presence of different amounts of $\mathrm{ZrP} / \mathrm{AgBr}$ per mL RhB: $1.1 \mathrm{mg}$ (A); $0.73 \mathrm{mg}$ (B); $0.45 \mathrm{mg}$ (C). 
The relative concentration of $\mathrm{RhB}$, de-ethylated and cleaved species as a function of time was calculated for the catalytic test carried out with the lowest amount of $\mathrm{ZrP} / \mathrm{AgBr}$ by applying Equation (2) to the absorbance values of Figure 9C; the results are shown in Figure 10.

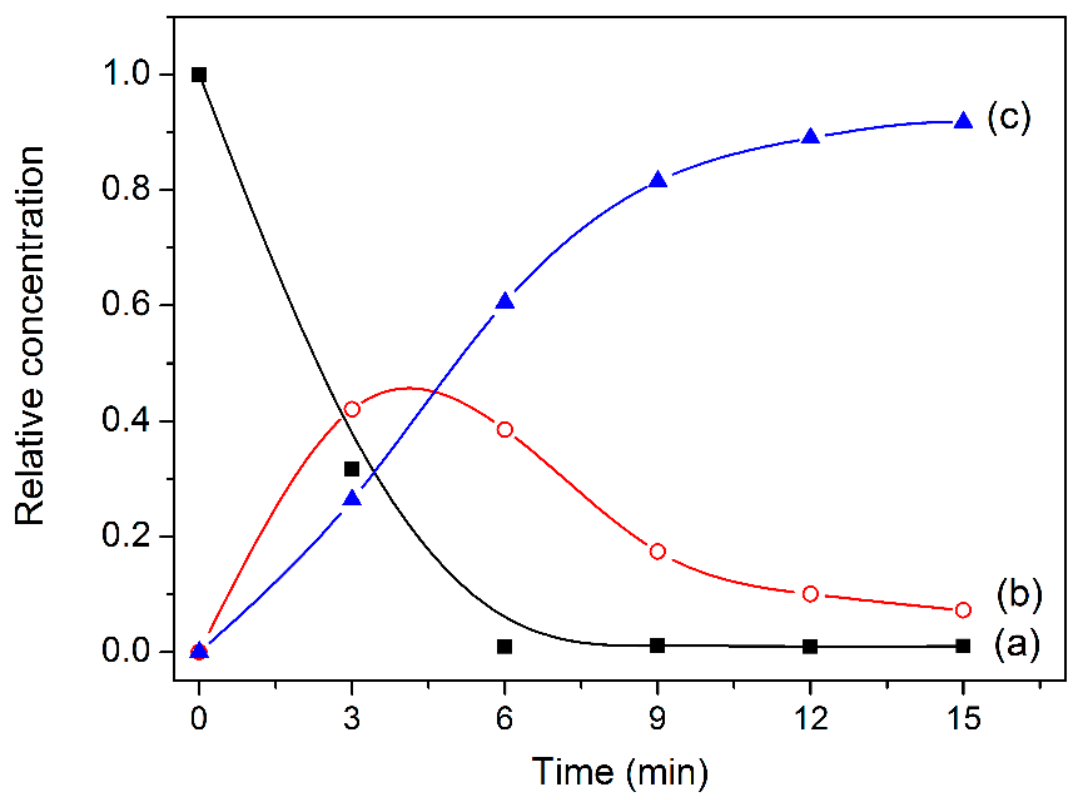

Figure 10. Relative concentration of $\operatorname{RhB}(a)$; de-ethylated species (b) and cleaved species (c) as a function of time, calculated according to Equation (2), for the catalytic test with $\mathrm{ZrP} / \mathrm{AgBr}$.

The general trends are similar to those observed for pure $\mathrm{AgBr}$, but the whole process is faster, with the half-life of RhB being $2.31 \mathrm{~min}$. At three minutes, de-ethylated species accounted for $42 \%$ of the initial concentration, while about $30 \%$ underwent cleavage. Cleavage clearly prevails over de-ethylation in the time range 6-15 $\mathrm{min}$.

It was also interesting to compare the results of the present paper with those obtained by Liang et al. in 2013 in the photocatalytic degradation of $\mathrm{RhB}$ by using $\mathrm{Ag} @ \mathrm{AgBr}$-intercalated $\mathrm{K}_{4} \mathrm{Nb}_{6} \mathrm{O}_{17}$ [20]. By using a comparable amount of photocatalyst (about $1 \mathrm{mg} / \mathrm{mL} \mathrm{RhB}$ ), they needed a much longer time (120 $\mathrm{min}$ ) in order to achieve a similar percentage of RhB photodegradation (about 96\%).

In order to assay the stability of the $\mathrm{ZrP} / \mathrm{AgBr}$ composite, three consecutive tests have been carried out with the highest amount of photocatalyst. Before each test, the recovered catalyst was washed with deionised water and dried over $\mathrm{P}_{2} \mathrm{O}_{5}$. The UV-Vis spectra collected during the second and third test are shown in Figure 11.

A slight loss of performance was observed after the first cycle, but the performance was in any case much higher with respect to that of fresh pure $\mathrm{AgBr}$, with the percentage of cleavage being around $90 \%$ after six minutes.

The XRD patterns of the catalyst sample recovered after each test and shown in Figure 12 did not highlight significant changes as a consequence of repeated cycles of irradiation. The enlarged view of the pattern around $38^{\circ} 2 \theta$ (see the inset of Figure 12) put in evidence the presence of a broad reflection of low intensity at $38.1^{\circ} 2 \theta$ after three cycles, which can be assigned to the (111) crystallographic plane of metallic silver, formed as a consequence of the sample irradiation. However, the fact that metallic silver is not clearly detected for at least three cycles suggested that the $\mathrm{ZrP} / \mathrm{AgBr}$ catalyst has a good stability toward light irradiation and this result is also confirmed by the fact that its performance remained high during the repeated catalytic tests. 

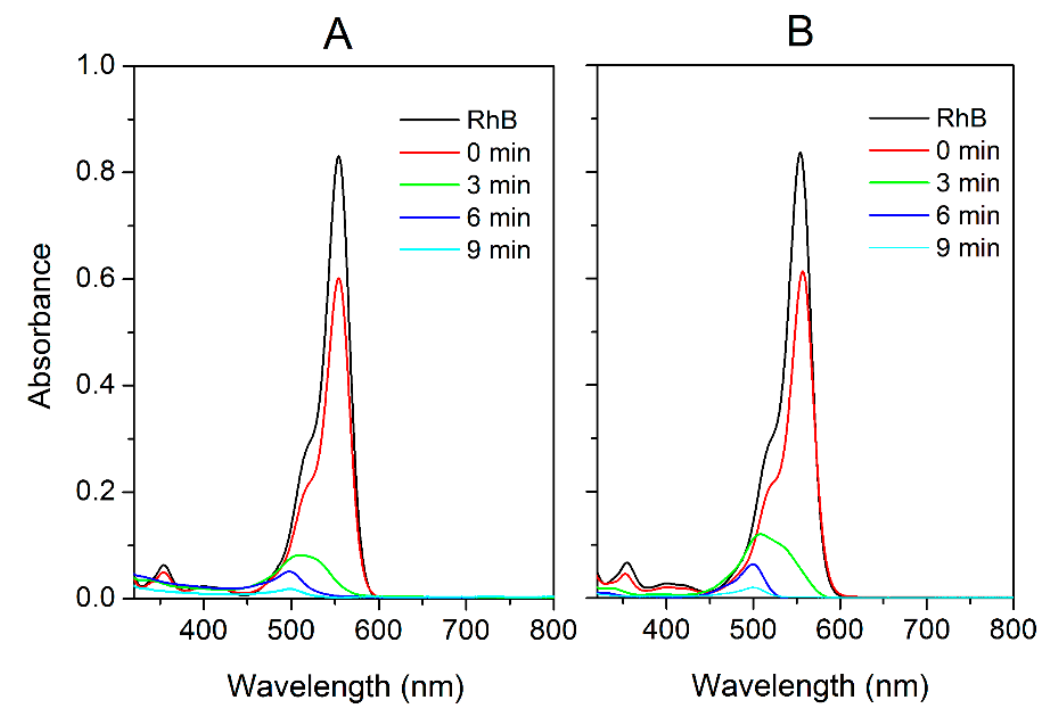

Figure 11. UV-Vis spectra collected during the second (A) and third (B) test carried out with $\mathrm{ZrP} / \mathrm{AgBr}$ (1.1 mg AgBr/ mL RhB).

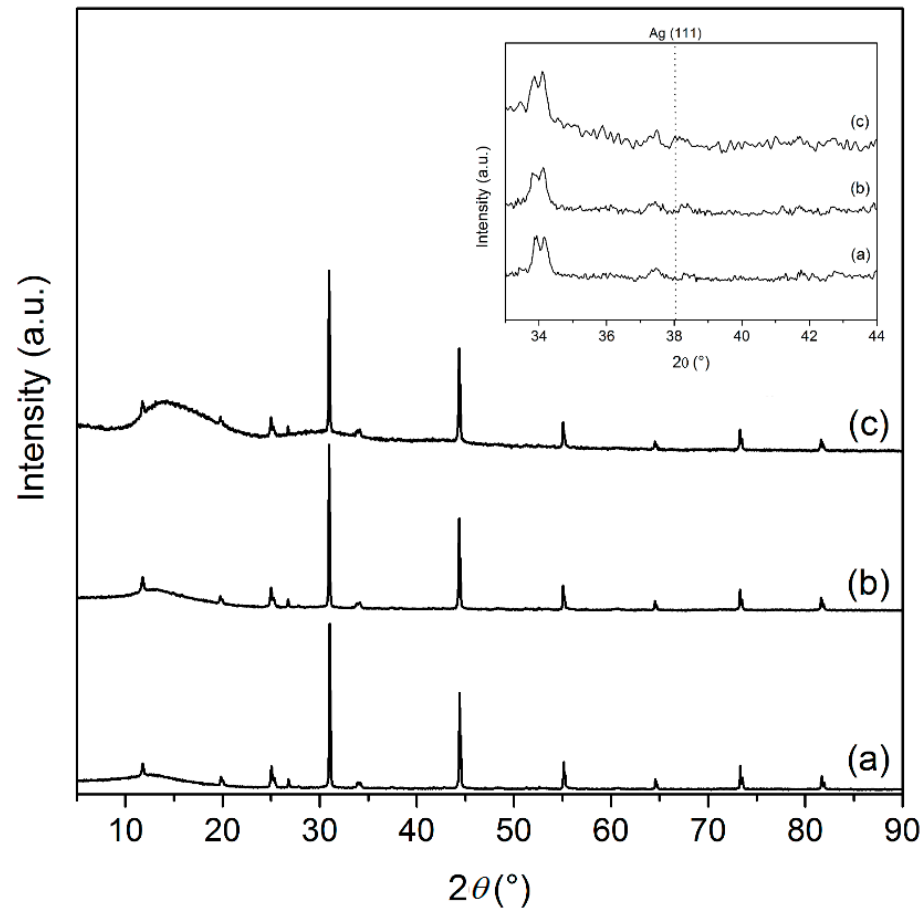

Figure 12. $\mathrm{XRD}$ patterns of the $\mathrm{ZrP} / \mathrm{AgBr}$ photocatalyst collected after the first (a); the second (b) and the third (c) catalytic test.

\subsection{Catalytic Behavior of $\mathrm{ZrP} /$ silver Halides}

In order to provide an overview on the catalytic behavior of $\mathrm{ZrP} /$ silver halide composites, kinetic data collected for the $\mathrm{AgCl}$ and $\mathrm{ZrP} / \mathrm{AgCl}$ catalysts (previously tested for the photodegradation of $\mathrm{RhB}$ [8]) have been analyzed by the same system of five linear equations used for AgBr-based catalysts, and the relative concentration of $\mathrm{RhB}$, de-ethylated and cleaved species were then calculated as a function of time. The obtained results are shown in Figures 13 and 14 for pure $\mathrm{AgCl}$ and for the $\mathrm{ZrP} / \mathrm{AgCl}$ composite containing about $58 \mathrm{wt} \% \mathrm{AgCl}$, respectively. 


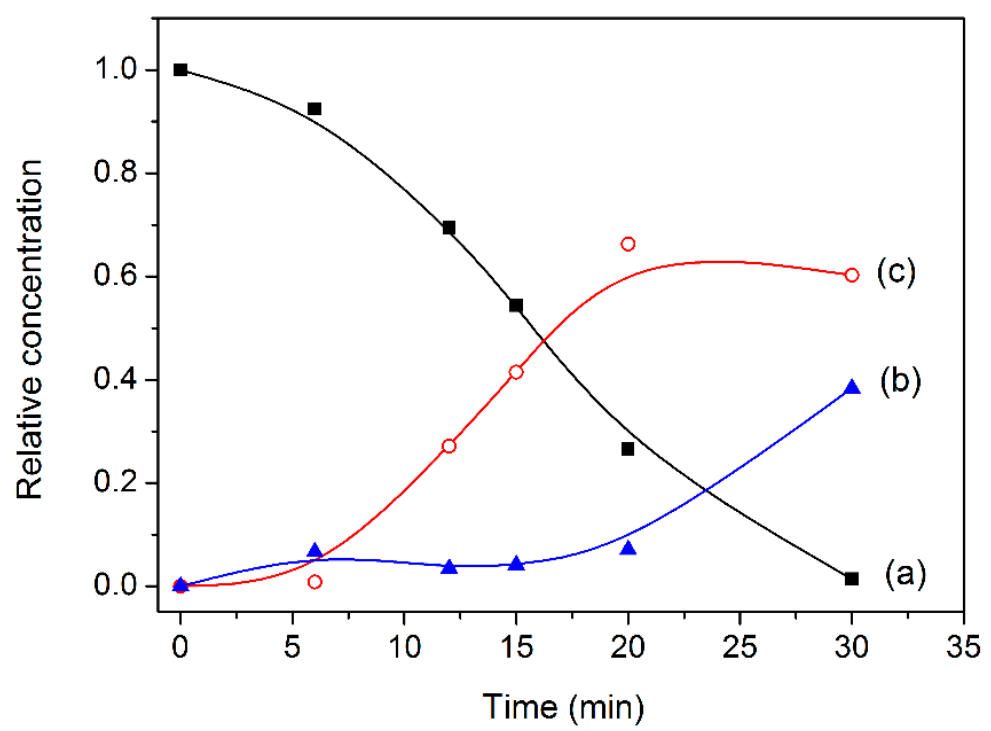

Figure 13. Relative concentration of $\operatorname{RhB}(\mathrm{a})$; de-ethylated species (b) and cleaved species (c) as a function of time, calculated according to Equation (2), for the catalytic test with pure AgCl.

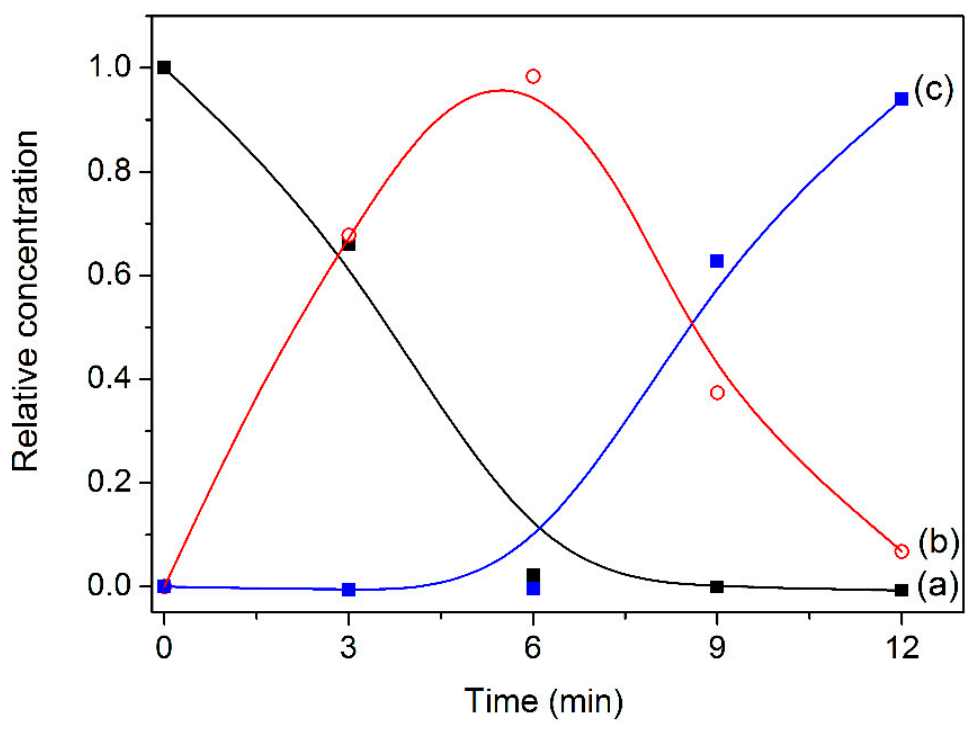

Figure 14. Relative concentration of $\operatorname{RhB}(\mathrm{a})$; de-ethylated species (b) and cleaved species (c) as a function of time, calculated according to Equation (2), for the catalytic test with $\mathrm{ZrP} / \mathrm{AgCl}$.

Compared to $\mathrm{AgBr}$, de-ethylation is basically the only process occurring within the first $20 \mathrm{~min}$. The difference between de-ethylation and cleavage is even more pronounced in the kinetics with $\mathrm{ZrP} / \mathrm{AgCl}$; as a matter of fact, the complete disappearance of $\mathrm{RhB}$, observed at six minutes, is entirely due to de-ethylation, while the de-ethylated species are cleaved in the time range 6-12 min.

The half-life of $\mathrm{RhB}$ was $15.8 \mathrm{~min}$ and $3.01 \mathrm{~min}$ for the kinetics with $\mathrm{AgCl}$ and $\mathrm{ZrP} / \mathrm{AgCl}$, respectively.

It is also observed that the relative rate of the cleavage, with respect to that of the de-ethylation, is higher for the AgBr-based catalysts than for those based on $\mathrm{AgCl}$.

To get further insights into the kinetics of the dye degradation for the different catalysts, the relative concentration of $\mathrm{RhB}$, calculated from the various experiments, was plotted as a function of $t / t_{1 / 2}$; the results are shown in Figure 15.

Surprisingly, all data sets lie along the same curve, suggesting that the first step of RhB photodegradation is the same for all four catalytic systems. Therefore, it is suggested that, as in 
the case of $\mathrm{ZrP} / \mathrm{AgCl}$, and now for $\mathrm{AgCl}, \mathrm{AgBr}$ and $\mathrm{ZrP} / \mathrm{AgBr}$, the degradation process starts with $\mathrm{RhB}$ de-ethylation, followed by cleavage of the de-ethylated species.

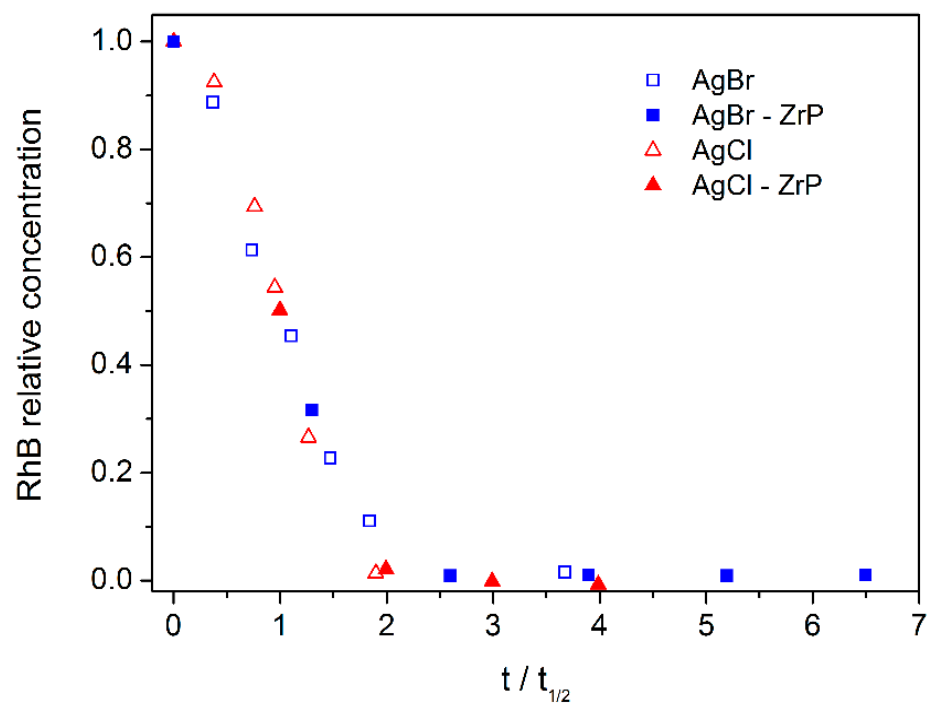

Figure 15. Relative concentration of $\mathrm{RhB}$ as a function of $t / t_{1 / 2}$, calculated from the catalytic tests carried out with $\mathrm{AgX}$ and $\mathrm{ZrP} / \mathrm{AgX}(\mathrm{X}=\mathrm{Cl}, \mathrm{Br})$ photocatalysts.

\section{Experimental}

\subsection{Chemicals}

Zirconyl propionate $\left(\mathrm{ZrO}_{1.26}\left(\mathrm{C}_{2} \mathrm{H}_{5} \mathrm{COO}\right)_{1.49}\right.$, molecular weight $\left.(\mathrm{MW})=220 \mathrm{Da}\right)$ was kindly supplied by MEL Chemicals, Manchester, UK. Concentrated orthophosphoric acid (85\%, $14.8 \mathrm{M})$ and propanol were purchased from Fluka (Milano, Italy) and Carlo Erba (Milano, Italy), respectively. All other reagents were from Aldrich (Milano, Italy) and used without further purification.

\subsection{Synthesis of the $\mathrm{ZrP} / \mathrm{AgBr}$ Composite}

Nanocrystalline $\mathrm{ZrP}$, prepared as reported in [21], was used for the synthesis of the $\mathrm{ZrP} / \mathrm{AgBr}$ composite. First, silver exchanged zirconium phosphate was prepared by a $\mathrm{H}^{+} / \mathrm{Ag}^{+}$ion exchange reaction, carried out as follows: $133 \mathrm{~mL}$ of a $5 \times 10^{-2} \mathrm{M}$ silver acetate solution was added to $1 \mathrm{~g}$ of nanocrystalline $\mathrm{ZrP}$ powder suspended in water, so that the $\mathrm{Ag} / \mathrm{Zr}$ molar ratio was 2.0. The mixture was left stirring in the dark at room temperature for five hours. The solid recovered after centrifugation was washed with water and dried at room temperature over $\mathrm{P}_{2} \mathrm{O}_{5}$. The $\mathrm{P} / \mathrm{Zr}$ and $\mathrm{Ag} / \mathrm{Zr}$ molar ratios, determined by Inductively Coupled Plasma Atomic Emission Spectroscopy ICP AES analysis, were 2.0 and 1.8, respectively, so that the following composition was assigned: $\mathrm{ZrAg}_{1.8} \mathrm{H}_{0.2}\left(\mathrm{PO}_{4}\right)_{2}$ (hereafter indicated as $\mathrm{ZrPAg}$ ).

$\mathrm{AgBr}$ was formed by the reaction of $\mathrm{ZrPAg}$ with an excess of $0.5 \mathrm{M} \mathrm{HBr}(\mathrm{Br} / \mathrm{Ag}$ molar ratio $\approx 30)$ and then washed with $1 \times 10^{-3} \mathrm{M} \mathrm{HBr}$. After the reaction, the solid (hereafter indicated as $\mathrm{ZrP} / \mathrm{AgBr}$ ) changed its color from white to pale yellow, due to the presence of $\mathrm{AgBr}$. The $\mathrm{ZrP} / \mathrm{AgBr}$ composite was finally dried at room temperature over $\mathrm{P}_{2} \mathrm{O}_{5}$. The weight percent of $\mathrm{AgBr}$ in the composite, calculated from the $\mathrm{Ag} / \mathrm{Zr}$ molar ratio of the corresponding $\mathrm{ZrPAg}$ precursor, was $53 \mathrm{wt} \%$.

A sample of pure $\mathrm{AgBr}$, which was used as reference material, was precipitated by the reaction of silver acetate with an excess of $0.5 \mathrm{M} \mathrm{HBr}(\mathrm{Br} / \mathrm{Ag}$ molar ratio $\approx 30)$; the solid was then washed with $1 \times 10^{-3} \mathrm{M} \mathrm{HBr}$ and finally dried at room temperature over $\mathrm{P}_{2} \mathrm{O}_{5}$. All materials were sheltered from light before the catalytic tests. 


\subsection{Techniques}

Before the catalytic tests, the powder samples were characterized by inductively coupled plasma-optical emission spectrometry (ICP-OES), X-ray diffraction (XRD) analysis, transmission electron microscopy (TEM) analysis and diffusive reflectance spectroscopy (DRS).

An ICP-OES Varian Liberty spectrometer with axial injection was used to determine the $\mathrm{P} / \mathrm{Zr}$ and $\mathrm{Ag} / \mathrm{Zr}$ molar ratio in $\mathrm{ZrPAg}$. A weighed amount of the samples was dissolved in $3 \mathrm{M} \mathrm{HF}(\approx 2 \mathrm{~mL})$ and then diluted with water.

XRD analysis was carried out with a Philips X'Pert PRO MPD diffractometer (Malvern Panalytical, Malvern, UK) operating at $40 \mathrm{kV}$ and $40 \mathrm{~mA}$, and using $\mathrm{Cu} \mathrm{K \alpha}$ radiation and an $\mathrm{X}^{\prime}$ Celerator detector; the step size was $0.0167^{\circ}$ and the counting time was $50 \mathrm{~s}$.

SEM analysis was performed by a Zeiss LEO 1525 FE SEM (Zeiss, Jena, Germany), at the LUNA Laboratory of the Department of Physics and Geology of Perugia University. The powder samples were put on an aluminum stub pre-coated with a double sided adhesive conductive carbon tape and coated with a thin layer of chromium.

Diffusive reflectance measurements were carried out by a portable spectrophotometer composed of Avantes parts and a deuterium-halogen lamp (AvaLight-DH-2000-FHS, Avantes, Apeldoorn, The Netherlands). An integrating sphere with a $6 \mathrm{~mm}$ diameter viewing aperture and 88 irradiation angle (ISP-30-6) was used to collect and transfer the reflectance signals to an AvaSpec-2048 charge-coupled device $(C C D)$ detector via a quartz fiber-optic system (diameter $=600 \mu \mathrm{m}$ ). The acquisition of the spectra in the range $200-1100 \mathrm{~nm}$ was controlled by the AvaSoft software (Version 8 Avantes, Apeldoorn, The Netherlands).

The reflectance values were transformed to Kubelka-Munk units according to Equation (3) [22]:

$$
\frac{K}{S}=\frac{\left[1-R_{\lambda_{0}}\right]^{2}}{2 R_{\lambda_{0}}}=F\left(R_{\lambda_{0}}\right)
$$

where $K$ and $S$ represent the apparent absorption and scattering coefficients, respectively, and are functions of wavelength; $R_{\lambda 0}$ is the reflectance value experimentally recorded at $\lambda_{0}$; and $F\left(R_{\lambda 0}\right)$ is the so-called re-emission function at $\lambda_{0}$.

To discern direct and indirect electronic transitions, Equation (4) was used:

$$
\alpha h v=B\left(h v-E_{g}\right)^{n}
$$

where $\alpha, v, B, E_{g}$ are the absorption coefficient (proportional to the $\mathrm{K} / \mathrm{S}$ ratio, assuming $\mathrm{S}$ is wavelength-independent), the light frequency, a proportional constant, and the band gap energy, respectively. The exponential $n$ rules the character of the transition, which is direct for $n=\frac{1}{2}$, and indirect for $n=2$ [23]. In order to distinguish these two kinds of transitions, Equation (2) was rearranged and $[(K / S) h v]^{1 / n}$ was plotted as a function of $h v$, obtaining a straight line (Equation (5)):

$$
\left[\left(\frac{K}{S}\right) h v\right]^{1 / n} \propto B^{1 / n} h v-B^{1 / n} E_{g}
$$

The ratio between the intercept and the slope gave the right band gap for only one value of $n$, either $1 / 2$ or 2 .

The photocatalytic tests were performed by studying the photodegradation of Rhodamine $B(\mathrm{RhB})$ dye. With this aim, a $1 \times 10^{-5} \mathrm{M} \mathrm{RhB}$ aqueous solution was prepared. Then, a weighted amount of catalyst powder was suspended in $25 \mathrm{~mL}$ of this solution and the mixture was left stirring in the dark for $30 \mathrm{~min}$ in order achieve the adsorption equilibrium of the dye onto the catalyst surface. The mixture was irradiated with a $105 \mathrm{~W}$ Osram halogen lamp with a UV filter (providing radiation with $\lambda \geq 350 \mathrm{~nm}$ ). It was calculated that the UV light emitted by the lamp is less than $2 \%$ of the visible light. The sample illumination area was $16 \mathrm{~cm}^{2}$ and the distance between the light source and the upper 
surface of the liquid was $7.5 \mathrm{~cm}$. The RhB degradation over time was studied by taking up, during irradiation, suitable portions of the mixture, which was centrifuged to separate the solid catalyst from the solution, and then analyzed by a UV-Vis spectrometer. The amount of catalyst used for the catalytic tests has been reported in Table 1 .

\section{Conclusions}

A zirconium phosphate/silver bromide ( $\mathrm{ZrP} / \mathrm{AgBr}$ ) composite, containing $53 \mathrm{wt} \%$ of $\mathrm{AgBr}$, was prepared by the reaction of hydrobromic acid with silver exchanged $\mathrm{ZrP}$. The $\mathrm{AgBr}$ particles in $\mathrm{ZrP} / \mathrm{AgBr}$ are smaller than those of a pure $\mathrm{AgBr}$ sample, synthesized in similar conditions from homogeneous solution.

The photocatalytic properties of pure $\mathrm{AgBr}$ and $\mathrm{ZrP} / \mathrm{AgBr}$ were tested in the photocatalytic degradation of $\mathrm{RhB}$, which was faster with $\mathrm{ZrP} / \mathrm{AgBr}$ than with pure $\mathrm{AgBr}$ with the amount of $\mathrm{AgBr}$ being the same or even lower. $\mathrm{ZrP} / \mathrm{AgBr}$ performed well for at least three consecutive catalytic tests.

Moreover, the visible spectra of the RhB solution at different irradiation times were decomposed in order to determine the relative concentrations of $\mathrm{RhB}$, de-ethylated and cleaved species as a function of time. It was found that the dye was degraded according to two consecutive reactions: stepwise de-ethylation, followed by cleavage of the chromophore structure. The catalytic data obtained for $\mathrm{AgBr}$ and $\mathrm{ZrP} / \mathrm{AgBr}$ were compared with those of the $\mathrm{AgCl}$ and $\mathrm{ZrP} / \mathrm{AgCl}$ systems, finding that, in comparison with the de-ethylation rate, the cleavage rate is higher for the $\mathrm{AgBr}$-based catalysts than for those based on $\mathrm{AgCl}$.

Supplementary Materials: The following are available online at http:/ /www.mdpi.com/2073-4344/9/1/3/s1, Figure S1: SEM pictures of (A) microcrystalline $\mathrm{ZrP} / \mathrm{AgCl}$ at different magnifications and (B) nanocrystalline $\mathrm{ZrP} / \mathrm{AgCl}$ (unpublished images).

Author Contributions: M.P. designed the work, elaborated the experimental data, wrote and revised the manuscript. M.C. elaborated the experimental data, wrote and revised the manuscript. M.N. designed the work and revised the paper. A.D. revised the paper. S.C. made the experiments. P.L.G. made the DRS measurements and contributed to write and revise the manuscript.

Funding: This research received no external funding.

Conflicts of Interest: The authors declare no conflict of interest.

\section{References}

1. Hussain, F.; Hojjati, M.; Okamoto, M.; Gorga, R.E. Review article: Polymer-matrix Nanocomposites, Processing, Manufacturing, and Application: An Overview. J. Compos. Mater. 2006, 40, 1511-1575. [CrossRef]

2. Xie, Z.; Liu, Z.; Wang, Y.; Yang, Q.; Xu, L.; Ding, W. An Overview of Recent Development in Composite Catalysts from Porous Materials for Various Reactions and Processes. Int. J. Mol. Sci. 2010, 11, $2152-2187$. [CrossRef] [PubMed]

3. Carrara, N.; Badano, J.M.; Betti, C.; Lederhos, C.; Busto, M.; Vera, C.; Quiroga, M. New Strategies for Obtaining Inorganic-Organic Composite Catalysts for Selective Hydrogenation, New Advances in Hydrogenation Processes, Maryam Takht Ravanchi; IntechOpen: Rijeka, Croatia, 2017; Available online: http:/ /www.webcitation.org/ 73nRHpWaa (accessed on 9 November 2018). [CrossRef]

4. Pica, M. Zirconium Phosphate Catalysts in the XXI Century: State of the Art from 2010 to Date. Catalysts 2017, 7, 190. [CrossRef]

5. Pica, M.; Donnadio, A.; Casciola, M. From microcrystalline to nanosized $\alpha$-zirconium phosphate: Synthetic approaches and applications of an old material with a bright future. Coord. Chem. Rev. 2018, 374, $218-235$. [CrossRef]

6. Clearfield, A.; Costantino, U. Layered metal phosphates and their intercalation chemistry. In Comprehensive Supramolecular Chemistry, Solid-state Supramolecular Chemistry: Two-and Three-Dimensional Inorganic Networks; Alberti, G., Bein, T., Eds.; Pergamon: Oxford, UK, 1996; Volume 7, Chapter 4.

7. Petrucci, C.; Cappelletti, M.; Piermatti, O.; Nocchetti, M.; Pica, M.; Pizzo, F.; Vaccaro, L. Immobilized palladium nanoparticles on potassium zirconium phosphate as an efficient recoverable heterogeneous catalyst for a clean Heck reaction in flow. J. Mol. Catal. A Chem. 2015, 401, 27-34. [CrossRef] 
8. Pica, M.; Nocchetti, M.; Ridolfi, B.; Donnadio, A.; Costantino, F.; Gentili, P.L.; Casciola, M. Nanosized zirconium phosphate/ $\mathrm{AgCl}$ composite materials: A new synergy for efficient photocatalytic degradation of organic dye pollutants. J. Mater. Chem. A 2015, 3, 5525-5534. [CrossRef]

9. Wang, P.; Huang, B.; Daia, Y.; Whangbo, M.-H. Plasmonic photocatalysts: Harvesting visible light with noble metal nanoparticles. Phys. Chem. Chem. Phys. 2012, 14, 9813-9825. [CrossRef] [PubMed]

10. Xia, Y.; Halas, N.J. Shape-Controlled Synthesis and Surface Plasmonic Properties of Metallic Nanostructures. MRS Bull. 2005, 30, 338-348. [CrossRef]

11. Jiang, R.; Li, B.; Fang, C.; Wang, J. Metal/Semiconductor Hybrid Nanostructures for Plasmon-Enhanced Applications. Adv. Mater. 2014, 26, 5274-5309. [CrossRef] [PubMed]

12. Wang, P.; Huang, B.; Qin, X.; Zhang, X.; Dai, Y.; Wei, J.; Whangbo, M.-H. Ag@AgCl: A Highly Efficient and Stable Photocatalyst Active under Visible Light. Angew. Chem. Int. Ed. 2008, 47, 7931-7933. [CrossRef] [PubMed]

13. Wang, P.; Huang, B.; Lou, Z.; Zhang, X.; Qin, X.; Dai, Y.; Zheng, Z.; Wang, X. Synthesis of Highly Efficient $\mathrm{Ag} @ \mathrm{AgCl}$ Plasmonic Photocatalysts with Various Structures. Chem.-A Eur. J. 2010, 16, 538-544. [CrossRef] [PubMed]

14. Han, L.; Wang, P.; Zhu, C.; Zhai, Y.; Dong, S. Facile solvothermal synthesis of cube-like Ag@AgCl: A highly efficient visible light photocatalyst. Nanoscale 2011, 3, 2931-2935. [CrossRef] [PubMed]

15. An, C.; Wang, S.; Sun, Y.; Zhang, Q.; Zhang, J.; Wang, C.; Fang, J. Plasmonic silver incorporated silver halides for efficient photocatalysis. J. Mater. Chem. A 2016, 4, 4336-4352. [CrossRef]

16. Jiang, J.; Li, H.; Zhang, L. New insight into daylight photocatalysis of AgBr@ Ag: Synergistic effect between semiconductor photocatalysis and plasmonic photocatalysis. Chem.-A Eur. J. 2012, 18, 6360-6369. [CrossRef] [PubMed]

17. Chen, F.; Zhao, J.; Hidaka, H. Highly selective deethylation of rhodamine B: Adsorption and photooxidation pathways of the dye on the $\mathrm{TiO}_{2} / \mathrm{SiO}_{2}$ composite photocatalyst. Int. J. Photoenergy 2003, 5, 210-217. [CrossRef]

18. Watanabe, T.; Takirawa, T.; Honda, K. Photocatalysis through Excitation of Adsorbates. Rhodamine B Adsorbed to CdS. J. Phys. Chem. 1977, 81, 1845-1851. [CrossRef]

19. De Mello Donegá, C. Synthesis and properties of colloidal heteronanocrystals. Chem. Soc. Rev. 2011, 40, 1512-1546. [CrossRef] [PubMed]

20. Cui, W.; Wang, H.; Liang, Y.; Han, B.; Liu, L.; Hu, J. Microwave-assisted synthesis of Ag@AgBr-intercalated $\mathrm{K}_{4} \mathrm{Nb}_{6} \mathrm{O}_{17}$ composite and enhanced photocatalytic degradation of Rhodamine $\mathrm{B}$ under visible light. Chem. Eng. J. 2013, 230, 10-18. [CrossRef]

21. Pica, M.; Donnadio, A.; Capitani, D.; Vivani, R.; Troni, E.; Casciola, M. Advances in the chemistry of nanosized zirconium phosphates: A new mild and quick route to the synthesis of nanocrystals. Inorg. Chem. 2011, 50, 11623-11630. [CrossRef] [PubMed]

22. Kortuem, G. Reflectance Spectroscopy; Springer: Berlin/Heidelberg, Germany; New York, NY, USA, 1969.

23. Tauc, J.; Grigorovici, R.; Vancu, A. Optical properties and electronic structure of amorphous germanium. Phys. Stat. Sol. 1966, 15, 627-637. [CrossRef]

(C) 2018 by the authors. Licensee MDPI, Basel, Switzerland. This article is an open access article distributed under the terms and conditions of the Creative Commons Attribution (CC BY) license (http://creativecommons.org/licenses/by/4.0/). 